\title{
A phase I trial of high-dose palliative radiotherapy plus concurrent weekly Vinorelbine and Cisplatin in patients with locally advanced
} and metastatic NSCLC

\author{
M Michael,', A Wirth², DL Ball', M MacManus², D Rischin', L Mileshkin', B Solomon', J McKendrick ${ }^{3}$ and \\ AD Milner ${ }^{4}$
}

'The Division of Haematology and Medical Oncology, Peter MacCallum Cancer Centre, Locked Bag I, A'Beckett St, Victoria 8006, Australia; ${ }^{2}$ The Division of Radiation Oncology, Peter MacCallum Cancer Centre, Locked Bag I, A'Beckett St, Victoria 8006, Australia; ' Department of Medical Oncology, Box Hill Hospital, Nelson Rd, Box Hill, Victoria 31 28, Australia; ${ }^{4}$ Centre for Biostatistics and Clinical Trials, Peter MacCallum Cancer Centre, Locked Bag I,

A'Beckett St, Victoria 8006, Australia

The role of concurrent chemoradiotherapy (CRT) in patients with non-small-cell lung cancer (NSCLC) unsuitable for radical therapy but who require locoregional treatment has not been defined. The aims of this phase I trial were thus to develop a novel regimen of weekly chemotherapy concurrent with high-dose palliative RT (40 Gy/20 fractions) and assess its tolerability, objective and symptomatic response rates. Eligible patients had stage I-IIIB NSCLC unsuitable for radical RT or limited stage IV disease, ECOG $P S \leqslant I$ and required locoregional therapy. Treatment was RT (40 Gy/20 fractions/5 per week) and weekly Vinorelbine plus Cisplatin escalated in six planned dose levels (DLs). At 4 weeks post-RT, patients received two cycles of Cisplatin $80 \mathrm{mgm}^{-2}$ day I + Vinorelbine $25 \mathrm{mg} \mathrm{m}^{-2}$ days I, 8, I5. Dose-limiting toxicities (DLTs) were defined in the CRT phase. Disease-related symptoms were assessed by the Lung Cancer Symptom Scale. In all, 24 patients accrued, stage IIIB $(n=12)$ and IV disease $(n=10)$. The highest administered dose was at DL 4, Vinorelbine $30 \mathrm{mg} \mathrm{m}^{-2}+$ Cisplatin $20 \mathrm{mg} \mathrm{m}^{-2}$ with DLTs of grade 4 neutropenia in two of three patients. No grade 3 or 4 nonhaematological toxicities were observed. The overall radiological response rate was 65\% ( $n=23$ : complete response $4 \%$ and partial response $61 \%)$ and infield FDG-PET responses were seen in $89 \%(n=18)$. There was an improvement or stabilisation of symptoms and quality of life. Dose level 3, Vinorelbine $25 \mathrm{mg} \mathrm{m}^{-2}+\mathrm{Cisplatin} 20 \mathrm{mg} \mathrm{m}^{-2}$, is recommended for further assessment. This regimen was tolerable and produced meaningful responses for patients for whom locoregional control is required, but who are unsuitable for radical CRT.

British Journal of Cancer (2005) 93, 652-66I. doi: I0.1038/sj.bjc.6602759 www.bjcancer.com

Published online 6 September 2005

(c) 2005 Cancer Research UK

Keywords: lung cancer; high-dose palliative radiotherapy; chemoradiotherapy; palliative benefit

The majority of patients with unresectable stage IIIA or IIIB nonsmall-cell lung cancer (NSCLC) are precluded from radical curative chemoradiotherapy (CRT) either due to the presence of extensive intrathoracic disease, poor performance status or significant comorbidities. A subgroup who have good performance status, limited metastatic involvement and require palliation of local symptoms have been treated with various regimens of high-dose palliative radiotherapy (HDPR), ranging from $30 \mathrm{~Gy}$ in 10 fractions to $42 \mathrm{~Gy}$ in 15 fractions or equivalent (MRC Lung Cancer Working Party, 1992; Macbeth et al, 1996; Ball et al, 1997; Plataniotis et al, 2002; Kramer et al, 2003; Sundstrom et al, 2004). High-dose palliative radiotherapy has been shown to provide an excellent palliative benefit through the reduction of local symptoms in $80-$ $90 \%$ of patients, and also benefits in terms of global quality of life

\footnotetext{
*Correspondence: Dr M Michael; E-mail: michael.michael@petermac.org Presented in part at the 27th Congress of the European Society of Medical Oncology, October 2002, Nice, France

Received 5 January 2005; revised 3 May 2005; accepted 2 August 2005; published online 6 September 2005
}

(QOL) (Schaafsma and Coy, 2000; Bezjak et al, 2002; Sundstrom et al, 2004).

A widely utilised alternative to HDPR has been the use of hypofractionated radiation schedules, which are considerably less resource and time intensive. However, a large retrospective analysis (Quddus et al, 2001) as well as randomised studies have confirmed that, relative to hypofractionated regimens, HDPR in patients with good performance status provides a greater benefit in terms of local symptom palliation, global QOL and survival, possibly in a dose-dependent manner (Simpson et al, 1985; Teo et al, 1988; Macbeth et al, 1996; Reinfuss et al, 1999; Gaze et al, 2001; Bezjak et al, 2002; Kramer et al, 2003). These observations though have not been consistent (MRC Lung Cancer Working Party, 1991; Nestle et al, 2000; Sundstrom et al, 2004).

Can the advances seen for radical CRT be translated to the HDPR setting, where the dominant competing risk for death is locoregional disease, that is, thoracic dominant disease? Randomised trials have demonstrated that the addition of platin-based chemotherapy to radiation is associated with a survival advantage when either given as induction (Sause et al, 1995; Dillman et al, 1996) or concurrent treatment (Schaake-Koning et al, 1992) 
compared to radiation alone. It is unclear whether combining concurrent chemotherapy with HDPR offers an advantage in terms of response, palliation and survival. Two studies have been reported exploring this approach, but with hypofractionated radiation regimens associated with significant toxicities (Jeremic et al, 1999; Slivano et al, 2000).

Vinorelbine is a vinca alkaloid with activity both as a single agent and in combination with platinum analogues in patients with NSCLC (Le Chevalier et al, 1994; Bunn and Kelly, 1998; The Elderly Lung Cancer Vinorelbine Italian Study Group, 1999). The agent is also a radiation sensitiser (Edelstein et al, 1996), which has led to its assessment in combination with platinum analogues and radical radiotherapy. The radiation and chemotherapy schedules have varied between studies; however, response rates have ranged from 62.5 to $80.4 \%$ (Masters et al, 1998; Hoffman et al, 2002; Vokes et al, 2002; Zatloukal et al, 2004).

The aims of this trial were thus to determine the highest administered dose of weekly Cisplatin and Vinorelbine combined with HDPR ( $40 \mathrm{~Gy}$ ) for patients with good performance status who were not suitable for radical CRT, assess the efficacy of this regimen by structural and functional imaging, and explore its effect upon disease-related symptoms (DRS). The secondary objectives were to determine the progression-free survival (PFS) and overall survival (OS) of patients treated with this regimen.

\section{MATERIALS AND METHODS}

\section{Patients}

Patients who met the following criteria were eligible: (1) histological or cytological proven NSCLC with measurable disease; (2) symptomatic locoregional disease; (3) unsuitable for radical CRT - examples include: (i) disease extent technically unsuitable for radical therapy, where the lung volumes encompassed by radiotherapy plans for $60 \mathrm{~Gy}$ were considered unacceptable, due to the need to include N3 disease (supraclavicular or contralateral mediastinal or hilar nodal involvement) or an excessive superior inferior disease extent, (ii) poor prognostic factors such as weight loss in excess of $10 \%$, (iii) concurrent medical illness or (iv) stage IV disease with limited extra-thoracic spread, where it is judged that the dominant competing risk for death is uncontrolled locoregional disease; (4) no prior radiotherapy or chemotherapy; (5) ECOG performance status $\leqslant 1$; (6) life expectancy in excess of 3 months; (7) adequate organ function - (i) hepatic: serum bilirubin $\leqslant 1.0 \times \mathrm{ULN}$, AST and/or ALT $\leqslant 2.0 \times \mathrm{ULN}$, ALP and GGT $\leqslant 2.5 \times$ ULN, if bone or liver involvement, AST or ALT, ALP and GGT $\leqslant 5.0 \times$ ULN, (ii) bone marrow: haemoglobin $\geqslant 100 \mathrm{gl}^{-1}$, neutrophil count $\geqslant 1.5 \times 10^{9} 1^{-1}$, platelet count $\geqslant 100 \times 10^{9} 1^{-1}$, (iii) renal: creatinine clearance $\geqslant 55 \mathrm{ml} \mathrm{min}^{-1}$ (using radioisotope renal scan or derived from serum creatinine using the Cockcroft-Gault formula); (8) age less than 75 years; (9) written informed consent.

The following patients were ineligible: (1) significant medical conditions which were considered to compromise the planned delivery of the chemotherapy and radiotherapy or be potentially exacerbated by these modalities; (2) history of any other cancer (except nonmelanoma skin cancer or carcinoma in situ of the cervix) unless in complete remission and off all therapy for that cancer for at least 5 years; (3) receiving treatment with another investigational agent. Institutional ethics committee approval was obtained.

\section{Treatment plan}

\section{Chemoradiotherapy}

1. Radiation therapy: All radiotherapy was administered using $6 \mathrm{MeV}$ linac, to a dose of $40 \mathrm{~Gy}$ in $2 \mathrm{~Gy}$ fractions, 5 per week for 4 weeks. The treatment plan was according to normal institutional practice, namely: (1) AP-PA treatment fields, (2) planning target volume $(\mathrm{PTV})=$ gross macroscopic disease $(\mathrm{GTV})+1 \mathrm{~cm}$, (3) dose specified at the midplane on the central axis; however, regions which may receive a greater dose by virtue of variation in patient contour (e.g. neck) were compensated using beam attenuators or mid-line shielding, to restrict the oesophageal dose to less than $42 \mathrm{~Gy}$. CT planning was not used routinely, unless there was concern regarding dose heterogeneity related to changes in contour, for example, proceeding from chest to neck, where the dose to the oesophagus could potentially be excessive or where the target volume required CT for accurate delineation. (4) Check films in weeks 1 and 2 of radiotherapy. If week 2 film was satisfactory, no further check films are required, otherwise repeat weekly.

2. Concurrent chemotherapy: During the external radiation therapy all patients received chemotherapy comprising of Cisplatin intravenous (i.v.) weekly and Vinorelbine i.v. days 1, 8, 22. Day 15 Vinorelbine was excluded due to the expected cumulative neutropenia from the prior doses.

The doses of each agent were escalated through six planned dose levels (DLs). Vinorelbine was escalated from 15 to $30 \mathrm{mg} \mathrm{m}^{-2}$ week $^{-1}$ and Cisplatin from 20 to $30 \mathrm{mg} \mathrm{m}^{-2}$ week $^{-1}$. All chemotherapy was given within $2 \mathrm{~h}$ of the delivery of the radiation fraction on that day. Premedication was standard. No pre- or post-hydration was utilised.

3. Definition of dose-limiting toxicities (DLTs): These were based on toxicities experienced during, and within, 2 weeks following CRT, and are defined as follows: (1) grade 4 neutropenia (ANC $<0.5 \times 10^{9} 1^{-1}$ ) of any duration; (2) grade 4 thrombocytopenia (platelet count $<10 \times 10^{9} 1^{-1}$ ) or grade 3 thrombocytopenia (platelet count $10-49 \times 10^{9} 1^{-1}$ ) with bleeding; (3) febrile neutropenia; (4) grade 3 or 4 nonhaematological toxicity (within or outside the radiation field), including nausea and vomiting despite adequate antinauseant therapy; (5) interruption of radiotherapy in excess of 1 week; (6) chemotherapy omitted for 1 or more weeks; (7) toxicity requiring one or more dose reductions during CRT.

4. Dose escalation schema: Three patients were planned to be entered into each DL. If no DLTs were observed in these three patients, the next DL was opened. If DLTs were observed in $\geqslant 2$ of three patients, then no further dose escalation took place. If DLTs were observed in one of three patients, then three additional patients (total of six patients) were accrued at this level. If DLTs were observed in $\leqslant 1$ of six patients, then the next DL was opened. If DLTs were observed in $\geqslant 2$ of six patients, no further dose escalation took place.

The highest administered dose was defined as that DL in which two or more of three or six patients had DLTs. The recommended DL (one below the highest administered dose) reached was expanded to a total of 15 patients to obtain further data concerning acute and late toxicities and response.

5. Dose modifications during CRT: Radiotherapy, together with chemotherapy, was suspended if the patient experienced grade 3 or 4 radiation-associated toxicities (e.g. oesophagus, lung, skin, heart). RT only was recommenced once reactions had improved to grade 1 or better within a maximum of 2 weeks.

During CRT, the chemotherapy doses were modified based on the worse grade of toxicities. Treatment modification was in two forms: either (a) permanent dose reductions or (b) treatment deferral with the recommencement at a reduced dose on recovery, that is, neutrophils $\geqslant 1.0 \times 10^{9} 1^{-1}$ or platelets $>50 \times 10^{9} 1^{-1}$, and nonhaematological toxicity to grade 1 . Patients entered at DL 1 requiring more than one dose reduction or entered at higher DLs requiring more than two dose reductions discontinued chemotherapy; however, the radiotherapy continued. 
Treatment was stopped early due to either disease progression, a greater than 2-week delay in radiotherapy delivery, unacceptable toxicity, patient request or patient noncompliance with the required investigations.

Consolidation chemotherapy At 4 weeks after completing CRT, all patients were planned to receive two cycles of chemotherapy, unless there was radiological progressive disease on restaging prior to this time. The chemotherapy consisted of Cisplatin $80 \mathrm{mg} \mathrm{m}^{-2}$ i.v. day 1 and Vinorelbine $25 \mathrm{mg} \mathrm{m}^{-2}$ i.v. weekly by three, the cycles were repeated every 28 days. The toxicities from these cycles were not used to determine the DLTs for CRT. Premedication and hydration regimens for Cisplatin and chemotherapy dose modifications were standard. On day 1 of each cycle, the following parameters were required: $\mathrm{ANC} \geqslant 1.5 \times 10^{9} 1^{-1}$, platelet count $\geqslant 100 \times 10^{9} 1^{-1}$ and creatinine clearance $\geqslant 55 \mathrm{ml} \mathrm{min}^{-1}$, and all nonhaematological toxicities resolved to at least grade 1 . If these were not achieved within 2 weeks, the patient ceased treatment.

\section{Monitoring procedures and tests}

At baseline (within 2 weeks of trial entry), patients had performance status recorded, bloods taken for full blood examination and differential and biochemistry (including serum urea, electrolytes and creatinine, calcium, liver function tests (bilirubin, AST/ALT, ALP, GGT)) and creatinine clearance estimation (using radioisotope renal scan or derived from serum creatinine using Cockcroft - Gault formula). Staging comprised of a chest X-ray PA/lateral, CT scan of the chest and upper abdomen, CT scan of the brain and bone scan if clinically indicated, FDGPET scan (optional, subject to availability), spirometry and the assessment of DRS by the Lung Cancer Symptom Scale (LCSS) (Hollen et al, 1993).

During treatment patients were reviewed weekly, with documentation of acute toxicities. Bloods were taken weekly as above, except for haematology, which was performed twice weekly during CRT. Creatinine clearance was estimated weekly during CRT and on day 1 of each course of consolidation chemotherapy. DRS were assessed weekly during CRT.

Tumour response (radiological and FDG-PET), spirometry and completion of the LCSS were repeated at 3 weeks post-CRT and 4 weeks post-completion of all therapy. Patients were then reviewed every 2 months for late radiation toxicities (RTOG/EORTC criteria), and restaging, (until documented progression or earlier if clinical suspicion) until death or loss to follow-up.

\section{Statistical analysis}

Criteria for the assessment of treatment outcomes and toxicities Tumour response: Radiological response was assessed as above, utilising the same methods as at baseline. The best overall radiological response within and outside the radiation field was documented using the WHO criteria (Miller et al, 1981).

Toxicities: Acute toxicities were assessed using the NCI Common Toxicity Criteria (version 2.0, 30 April 1999). Late radiation toxicities were assessed using the RTOG/EORTC criteria.

Statistical methods The worst grades of acute toxicities experienced during CRT, which were considered to be definitely or probably related to protocol treatment, were reported for all patients by DL using descriptive statistics. The overall response rate (complete $(\mathrm{CR})+$ partial responses $(\mathrm{PR})$ ) following CRT was estimated as the percentage of all patients, and its $95 \%$ confidence interval was estimated using the exact probabilities of the binomial distribution.

Disease-related. symptoms were assessed by the LCSS (Hollen et al, 1993). The patient subjective rating scale was used in these analyses and the data analysed as per the published methodology (Hollen et al, 1993). A Wilcoxon signed-rank test was used to find the difference in symptom scores before and after radiotherapy treatment. A two-sided $P<0.05$ was considered to be statistically significant.

All patients who commenced treatment were included in the analyses of PFS and OS. Patients were followed to a close-out date of 29 September 2003. Progression-free survival time was measured from the date of commencing protocol treatment to the date of first progression (local, regional of distant) or death without previous progression. Overall survival time was measured from the date of commencing protocol treatment to the date of death from any cause. The Kaplan-Meier method was used to estimate OS and PFS, with censoring of survival times at the closeout date. The Brookmeyer-Crowley method was used to estimate $95 \%$ confidence intervals for median survival times. The $95 \%$ confidence intervals for the percentages surviving at particular times were calculated using the logit transformation.

A potential follow-up time for each patient was defined as the time from commencing protocol treatment to the close-out date, unless the patient was lost to follow-up. A competing risks analysis was used to estimate cumulative incidence rates for different types of first progression.

\section{RESULTS}

\section{Patients}

In all, 24 patients were recruited from 30 June 2000 and 16 September 2003, from two oncology centres, across four DLs. Patient demographics are summarised in Table 1. Males predominated, with over $63 \%$ of patients being over 60 years of age. The majority, 22 patients (92\%), had stage IIIB or limited stage IV disease. Approximately $70 \%$ of patients had disease incorporated within the field due to mainly $\mathrm{N} 3$ disease (supraclavicular or contralateral hilar or mediastinal nodal involvement), while two patients had less extensive disease, but with adverse clinical or prognostic factors contraindicating radical therapy.

\section{Treatment delivery}

\section{Chemoradiotherapy}

1. Chemotherapy: A total of 24 patients were accrued across four DLs of weekly Cisplatin plus Vinorelbine: DL $1\left(15,20 \mathrm{mg} \mathrm{m}^{-2}\right.$, respectively), three patients; DL $2\left(20,20 \mathrm{mg} \mathrm{m}^{-2}\right)$, three patients; DL $3\left(25,20 \mathrm{mg} \mathrm{m}^{-2}\right), 15$ patients; DL $4\left(30,20 \mathrm{mg} \mathrm{m}^{-2}\right)$, three patients.

Dose level 4 was identified as the highest administered dose and hence DL 3, as discussed above, was expanded to a total sample of 15 patients.

Full dose delivery was achieved in DL 1 and 2, but dose omissions were observed in DL 3 and 4, specifically on days 15 and 22. The planned day 15 Cisplatin treatment was omitted in six patients due to the following reasons: grade 4 neutropenia in five (two in DL 4 and three in DL 3 ) and chest infection in one patient (DL 3). Vinorelbine was not planned to be administered on day 15. On day 22, both drugs were omitted in two patients in DL 3 , due to grade 3 neutropenia and persistent chest infection, respectively.

At the recommended DL, DL 3, the relative dose intensity (ratio of actual dose to planned dose) for the weekly Vinorelbine was 92\% (range 66.7-100\%) and for Cisplatin was $88.3 \%$, (range $50-$ $100 \%)$.

2 Radiotherapy: The planned total dose of $40 \mathrm{~Gy}$ was delivered to 23 or $96 \%$ of patients, with the remaining patient, receiving $30 \mathrm{~Gy}$ in 15 fractions, having refused to continue with treatment. In all, 19 or $79 \%$ of the patients completed the prescribed radiotherapy 
Table I Patient characteristics

\begin{tabular}{|c|c|c|}
\hline Characteristics & Number & $\%$ \\
\hline \multicolumn{3}{|l|}{ Sex } \\
\hline Male : female & $14: 10$ & $58: 42$ \\
\hline \multicolumn{3}{|l|}{ Age } \\
\hline Median & 65 & \\
\hline Range & $41-75$ & \\
\hline \multicolumn{3}{|l|}{ Histology } \\
\hline Squamous & 8 & 33 \\
\hline Adenocarcinoma & 8 & 33 \\
\hline Other & 8 & 33 \\
\hline \multicolumn{3}{|l|}{ Stage } \\
\hline I (T2No) & I & 4 \\
\hline$\| I A(T 3 N 2)$ & I & 4 \\
\hline IIIB $(\mathrm{TI}-3, \mathrm{~N} 3$ or $\mathrm{T} 4, \mathrm{~N} 0-3)$ & 12 & 50 \\
\hline IV $(\mathrm{TI}-4, \mathrm{NO}-3, \mathrm{MI})$ & 10 & 42 \\
\hline \multicolumn{3}{|l|}{ Distribution of $M I$ sites $(n=10)^{\mathrm{a}}$} \\
\hline Bone & 4 & 17 \\
\hline Lung (different lobe to primary) & 3 & 12 \\
\hline Adrenal & 2 & 8 \\
\hline Distant lymph node & 2 & 8 \\
\hline Pericardium & I & 4 \\
\hline Pleura & । & 4 \\
\hline \multicolumn{3}{|l|}{ Disease anatomy in relation to radiation field } \\
\hline Disease entirely inside field & 16 & 70 \\
\hline Disease inside/outside radiation field & 8 & 30 \\
\hline \multicolumn{3}{|l|}{ Weight loss over prior 3 months } \\
\hline None & 15 & 63 \\
\hline$\leqslant 10 \%$ & 9 & 38 \\
\hline \multicolumn{3}{|l|}{ ECOG performance status } \\
\hline 0 & 4 & 17 \\
\hline I & 18 & 75 \\
\hline 2 & 2 & 8 \\
\hline \multicolumn{3}{|c|}{ Presenting lung cancer symptoms as recorded by the $\operatorname{LCSS}(n=20)^{\mathrm{b}}$} \\
\hline Patients with $\geqslant 4$ symptoms & 17 & 85 \\
\hline Dyspnoea & 17 & 85 \\
\hline Haemoptysis & 7 & 35 \\
\hline Cough & 17 & 85 \\
\hline Pain & 14 & 70 \\
\hline Fatigue & 18 & 90 \\
\hline Anorexia & 17 & 85 \\
\hline
\end{tabular}

aPatients may have had more than one site of MI disease. ${ }^{\text {'Those who had }}$ symptoms $\geqslant 5 \mathrm{~mm}$ in the symptom scale were considered as symptom occurrence.

over the planned 28 days (5 days per week, weeks $1-4$ ). The reasons for a break in the planned treatment of five patients were: two patients with a febrile episode (nonfebrile neutropenia), one patient unwell, one patient unknown and one patient with refusal to continue.

3. Dose-limiting toxicities: These were prospectively defined and assessed only during the CRT dose escalation component of the treatment, as described above. The DLTs observed were haematological, where, in DL 4, two of the three patient cohort developed grade 4 neutropenia. Hence, DL 4 was determined to be the highest administered dose and DL 3 was defined as the recommended dose for expansion to 15 patients in total.

Consolidation chemotherapy Of the 24 patients entered, 20 had cycle 1 and 16 patients had both cycles 1 and 2 . Four patients had
Table 2 Haematological toxicities observed during concurrent chemoradiotherapy (NCl-CTC Version 2, 30 April 1999)

\begin{tabular}{|c|c|c|c|c|c|c|}
\hline \multirow[b]{2}{*}{ Toxicities } & \multirow[b]{2}{*}{$\begin{array}{l}\text { Worst } \\
\text { grade }\end{array}$} & \multicolumn{4}{|c|}{ Dose levels } & \multirow[b]{2}{*}{$\begin{array}{c}\text { Total } \\
(\%)\end{array}$} \\
\hline & & $\begin{array}{c}\text { I } \\
(n=3)\end{array}$ & $\begin{array}{c}2 \\
(n=3)\end{array}$ & $\begin{array}{c}3 \\
(n=15)\end{array}$ & $\begin{array}{c}4 \\
(n=3)\end{array}$ & \\
\hline \multirow[t]{2}{*}{ Leucocytes } & 3 & 0 & 0 & 4 & 3 & 7 (29) \\
\hline & 4 & 0 & 0 & 2 & 0 & $2(8)$ \\
\hline \multirow[t]{2}{*}{ Neutrophils } & 3 & 0 & 0 & 2 & 0 & $2(8)$ \\
\hline & 4 & 0 & 0 & 2 & 2 & $4(17)$ \\
\hline \multirow[t]{2}{*}{ Platelets } & 3 & 0 & 0 & 0 & 0 & $0(0)$ \\
\hline & 4 & 0 & 0 & 0 & 0 & $0(0)$ \\
\hline \multirow[t]{2}{*}{ Haemoglobin } & 3 & 0 & 0 & 0 & 0 & $0(0)$ \\
\hline & 4 & 0 & 0 & 0 & 0 & $0(0)$ \\
\hline
\end{tabular}

not received the planned first courses of consolidation therapy due to the following reasons: progressive disease (one patient), persistent chest infection (one patient), withdrawal of consent (one patient) and inadequate haematological recovery (one patient). Of the 20 patients who planned to receive the second course, four had not received therapy due to: persistent nausea and vomiting (one patient), febrile neutropenia (one patient), acute renal impairment (one patient) and unknown (one patient). The dose intensity overall for Cisplatin on day 1 was $96.2 \%$ and the Vinorelbine (days 1, 8, 15) was $73 \%$.

\section{Toxicity}

The haematological and nonhaematological toxicities from day 1 of CRT to the commencement of the first course of consolidation chemotherapy are detailed in Tables 2 and 3, respectively. The concurrent therapy was well tolerated overall. There were four patients who developed grade 4 neutropenia; however, only one developed febrile neutropenia. A further patient developed a chest infection. In terms of the nonhaematological toxicities, of note, there were no reported cases of grade 3 or 4 radiation oesophagitis or pulmonary toxicity.

In the 20 patients who proceeded onto consolidation chemotherapy, grade 4 neutropenia was observed in seven $(35 \%)$ patients, two patients each in DLs 2 and 4 and three in DL 3. Febrile neutropenia was observed in two patients (10\%), one each in DL 1 and 3, respectively. Other toxicities included sensory neuropathy, grade 2 in one patient in DL3, and grade 1 in two patients, one each in DLs 1 and 4 . Grade 3 renal impairment was observed in one patient in DL3.

The following late radiation toxicities, according to the EORTC/ RTOG criteria, were observed: (i) oesophageal: grade 1, one patient, DL1; grade 2, one patient, DL3; (ii) skin: grade 1, one patient, DL2 and (iii) lung: grade 1, one patient, DL1; grade 3, two patients, DL 1 and 3, respectively.

Spirometry was performed in patients at baseline $(n=24)$, at 3 weeks post-CRT $(n=18)$ and at the completion of all therapy $(n=11)$. The mean $\mathrm{FEV}_{1.0}$ at each of these time points was: $70.9 \%$ predicted (range $38-101 \%$ ), 74.5 and $62 \%$, respectively. The FVC at each of these time points was $86.2 \%$ predicted (range $51-124 \%$ ), 91.8 and $82 \%$, respectively.

\section{Response}

The overall radiological response data following the completion of all therapy (both within and outside the radiation field) are summarised in Table 4 . Of the 24 patients entered, 23 were evaluable for response, with one patient refusing to continue 
Table 3 Nonhaematological toxicities observed during concurrent chemoradiotherapy (NCl-CTC Version 2, 30 April 1999)

\begin{tabular}{|c|c|c|c|c|c|c|}
\hline \multirow[b]{2}{*}{ Toxicities } & \multirow[b]{2}{*}{$\begin{array}{l}\text { Worst } \\
\text { grade }\end{array}$} & \multicolumn{4}{|c|}{ Dose levels } & \multirow[b]{2}{*}{$\begin{array}{c}\text { Total } \\
\text { (\%) }\end{array}$} \\
\hline & & $\begin{array}{c}\text { I } \\
(n=3)\end{array}$ & $\begin{array}{c}2 \\
(n=3)\end{array}$ & $\begin{array}{c}3 \\
(n=15)\end{array}$ & $\begin{array}{c}4 \\
(n=3)\end{array}$ & \\
\hline $\begin{array}{l}\text { Febrile } \\
\text { neutropenia }\end{array}$ & 3 & 0 & 0 & 1 & 0 & I (4) \\
\hline $\begin{array}{l}\text { Fever without } \\
\text { grade } 3 \text { or } 4 \\
\text { neutropenia }\end{array}$ & 3 & 0 & 0 & 1 & 0 & I (4) \\
\hline Vomiting & 2 & 0 & 0 & 2 & 0 & $2(8)$ \\
\hline Fatigue & 3 & 0 & 1 & 2 & 0 & $3(13)$ \\
\hline Weight loss & 2 & 0 & I & 0 & 0 & I (4) \\
\hline $\begin{array}{l}\text { Inner earl } \\
\text { hearing }\end{array}$ & 2 & 1 & 0 & 0 & 0 & I (4) \\
\hline $\begin{array}{l}\text { Renal } \\
\text { impairment }\end{array}$ & 1 & 0 & 0 & I & 0 & I (4) \\
\hline $\begin{array}{l}\text { Radiation } \\
\text { dermatitis }\end{array}$ & 2 & 1 & 0 & 4 & 1 & $6(25)$ \\
\hline $\begin{array}{l}\text { Radiation } \\
\text { oesophagitis }\end{array}$ & 2 & 1 & I & 5 & 1 & $8(33)$ \\
\hline
\end{tabular}

Table 4 Radiological response following the completion of all therapies

\begin{tabular}{|c|c|c|c|c|c|}
\hline \multirow[b]{2}{*}{$\begin{array}{l}\text { Response parameters } \\
(n=23)\end{array}$} & \multicolumn{4}{|c|}{ Dose levels } & \multirow[b]{2}{*}{ No. (\%) } \\
\hline & $\begin{array}{c}\text { I } \\
(n=3)\end{array}$ & $\begin{array}{c}2 \\
(n=3)\end{array}$ & $\stackrel{3}{(n=14)}$ & $\begin{array}{c}4 \\
(n=3)\end{array}$ & \\
\hline \multicolumn{6}{|l|}{ Overall best response } \\
\hline Complete response & 0 & 0 & I & 0 & I (4\%) \\
\hline Partial response & 2 & 3 & 7 & 2 & $14(61 \%)$ \\
\hline Stable disease & 0 & 0 & 4 & 0 & $4(17 \%)$ \\
\hline Progressive disease & । & 0 & 0 & 1 & $2(9 \%)$ \\
\hline Not evaluable & 0 & 0 & 2 & 0 & $2(9 \%)$ \\
\hline \multicolumn{6}{|l|}{ Best response in radiation field } \\
\hline Complete response & 0 & 0 & 1 & 0 & I (4\%) \\
\hline Partial response & 2 & 3 & 7 & 2 & $14(61 \%)$ \\
\hline Stable disease & 0 & 0 & 4 & 0 & $4(17 \%)$ \\
\hline Progressive disease & 0 & 0 & 0 & I & I (4\%) \\
\hline Not evaluable & I & 0 & 2 & 0 & $3(13 \%)$ \\
\hline
\end{tabular}

treatment during CRT. Thus, of these 23 patients, the overall radiological response rate was $65 \%$ (15 of 23 ) (95\% confidence interval (CI): $34-77 \%$ ), with CR and PR rates of $4 \%$ (one of 23 ) and $61 \%$ (14 of 23 ), respectively. Stable disease was observed in $17 \%$ (four of 23 ), with progressive disease in two patients $(9 \%$ ), one outside and one inside the radiation field.

The radiological response rate within the radiation filed is also summarised in Table 4, with similar results as above. In all, $30 \%$ or eight patients had sites of disease that were not incorporated within the radiation field. Of these, a PR was observed in one patient and two patients had progressed outside the radiation field.

\section{Sites of relapse}

The location of first progression is detailed in Table 5. Of the 24 patients entered, local control was observed in 18 patients; however, regional nodal relapse (within or adjacent to the radiation field) was observed in 12 patients, with half being isolated without progression at other sites. Distant progression was observed in 13 (54\%) patients; in the majority of cases this was isolated without local or regional involvement. One patient had
Table 5 The location of first progression

\begin{tabular}{lcc}
\hline Location & N & \% ( $=\mathbf{2 4 )}$ \\
\hline Local $^{\mathrm{a}}$ & 2 & 8.3 \\
Regional $^{\mathrm{b}}$ & 6 & 25.0 \\
Distant $^{\mathrm{C}}$ & 9 & 37.5 \\
Local-regional $_{\text {Regional-distant }}$ & 2 & 8.3 \\
Local-regional-distant $_{\text {Death without progression }}$ & 2 & 8.3 \\
\hline
\end{tabular}

a Primary lesion. ${ }^{b}$ Relapse in (a) nodal stations within the radiation field, that is, involved hilar, mediastinal or supraclavicular nodes or (b) mediastinal or supraclavicular nodes adjacent to the radiation field. ${ }^{\mathrm{C}} \mathrm{MI}$ sites.

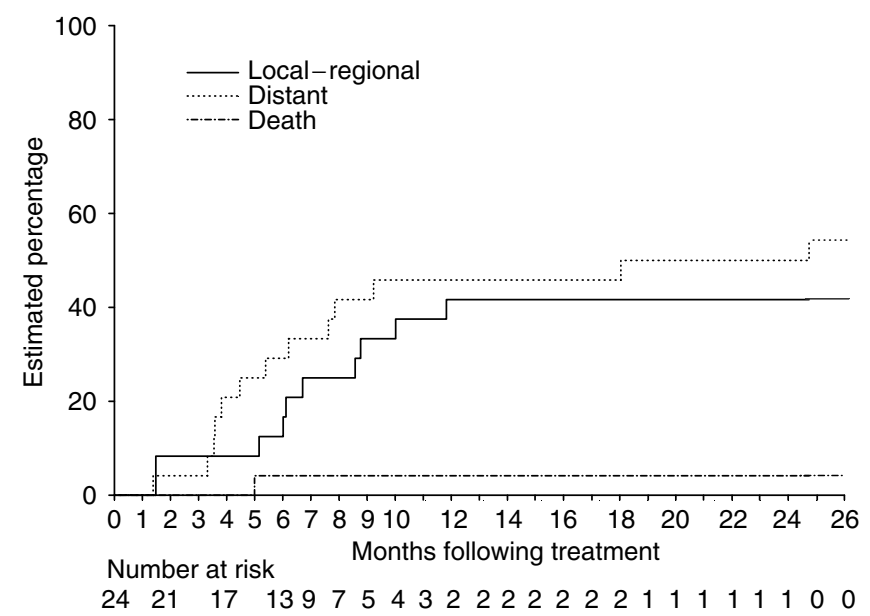

Figure I The cumulative incidence of first progress.

died without progression. The cumulative incidence of first progression is shown in Figure 1. The cumulative incidence of local-regional first progression at 6 and 12 months was 12.5 and $41.7 \%$, respectively, and for distant progression (alone or with locoregional progression) the risk was 29.2 and $45.8 \%$, respectively.

\section{Survival parameters}

Patients were followed up from commencing protocol treatment to a close-out date of 29 September 2003. One patient was lost to follow-up. The median potential follow-up time was 21.6 months (range 12.4-38.9 months), with all patients having progressed or died at the close-out date. The Kaplan-Meier PFS and OS survival curves are shown in Figure 2A and B. The actuarial PFS was 6.1 months (95\% CI 4.5-7.9 months), with the estimated PFS at 6 and 12 months being $54 \%$ (95\% CI $35-73 \%)$ and $8 \%$ (95\% CI $2-28 \%$ ), respectively.

The actuarial OS was 13.5 months (95\% CI $10.4->38.9$ months). The OS at 6, 12 and 24 months was $88 \%$ (95\% CI $68-$ $96 \%), 58 \%(95 \%$ CI $38-76 \%)$ and $34 \%$ (95\% CI $17-56 \%)$, respectively.

Of the 24 patients, 12 were classified as stage IIIB and 10 stage IV. The median OS for the stage IIIB and IV patients was $16.3(95 \%$ CI $10.4->38.9$ months) and 12.4 months (95\% CI $5.0->27.1$ months), respectively. The OS difference between the stages was not significant $(P=0.358)$.

\section{DRS and QOL}

Of the 24 patients entered, only 20 patients had LCSS data at baseline and 19 patients at 3 weeks post-CRT. The major 


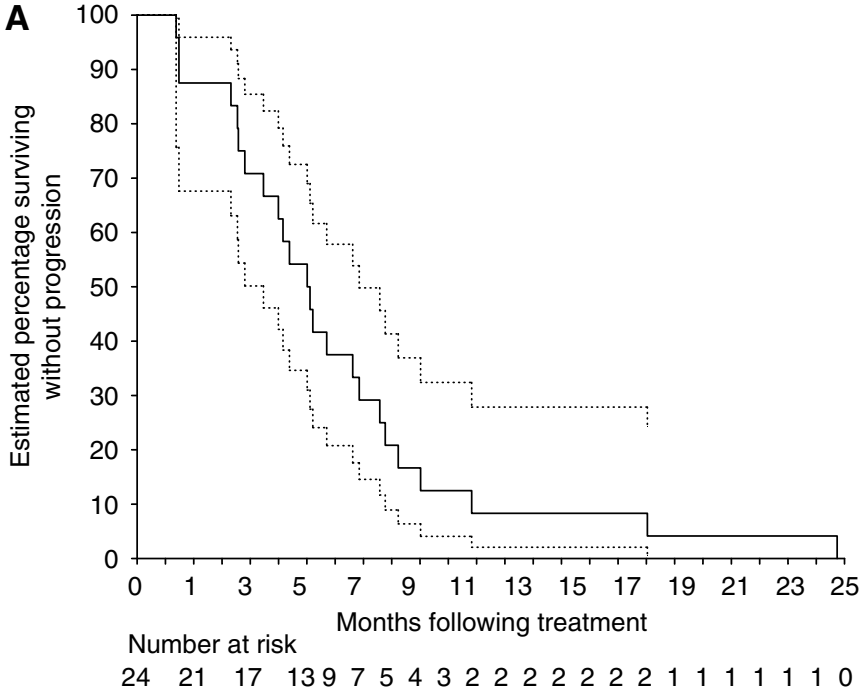

B

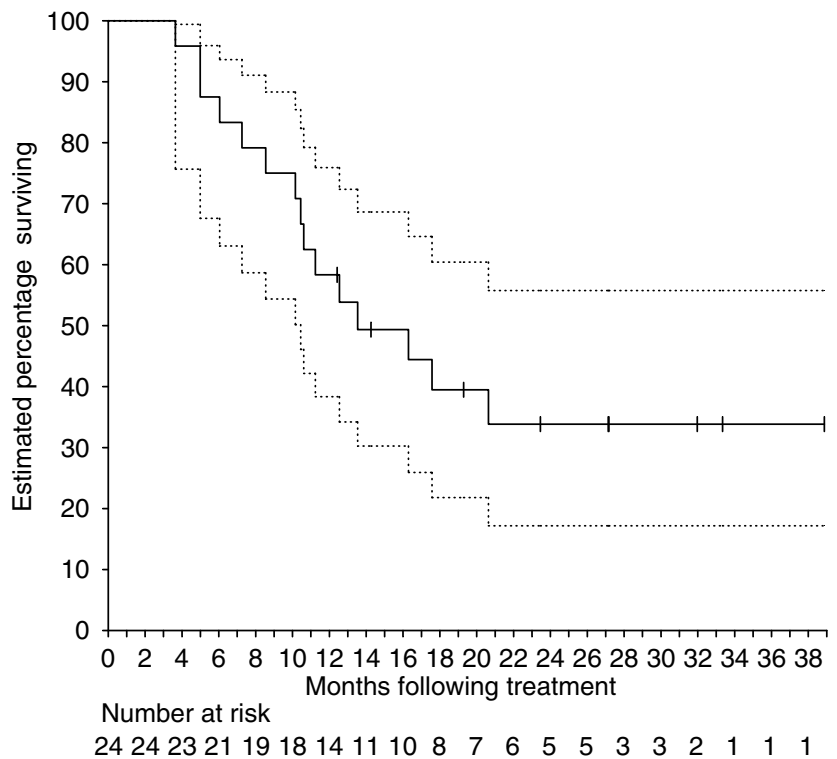

Figure 2 (A) Progression free-survival for all patients. (The hatched line represents the $95 \% \mathrm{Cl}$.) (B) The OS curve for all 24 patients. (The hatched line represents the $95 \% \mathrm{Cl}$.)

presenting symptoms are summarised in Table 1, with those due to local disease, including cough, pain and dyspnoea, being recorded by at least $70 \%$ of patients. Over $80 \%$ of patients had four or more symptoms at baseline, with $30 \%$ having six symptoms.

As shown in Figure 3, the post-CRT LCSS evaluation found that $30-50 \%$ of patients had an improvement in loss of appetite, cough and dyspnoea, with $37 \%$ of patients showing an improvement in overall symptom distress. A decline in scores was observed in up to $32 \%$ of patients subject to the parameters; for example, no patient had a decline or worsening of haemoptysis, but for $32 \%$ there was a deteriorating normal activity. A stabilisation of LCSS scores post-CRT was observed in $39-90 \%$ of patients, subject to the parameter.

Relative to baseline, at 3 weeks post-CRT, there was a nonsignificant trend towards improvement in scores for loss of appetite $(P=0.20)$, dyspnea $(P=0.13)$, haemoptysis $(P=0.14)$, pain $(P=0.36)$, overall symptomatic distress $(P=0.19)$ and overall QOL $(P=0.54)$ after CRT (Table 6). There was a statistically significant improvement in cough $(P=0.02)$ following CRT. The average LCSS score decreased after CRT (27.1 vs 21.2, $P=0.08$ ).

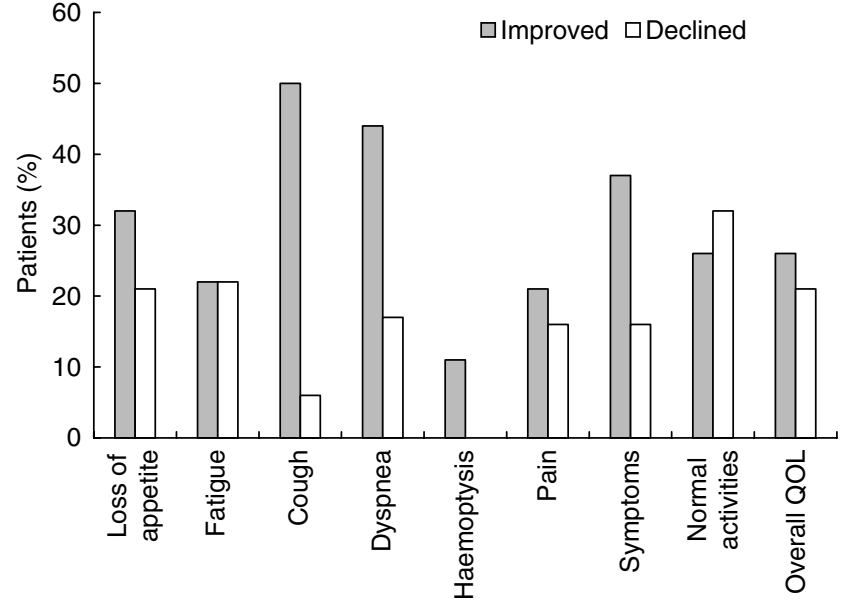

Figure 3 Change in LCSS scores between baseline and 3 weeks after CRT. (Improved: $>10 \mathrm{~mm}$ better score after CRT. Declined: $>10 \mathrm{~mm}$ worse score 3 weeks after CRT.)

Table 6 The descriptive statistics of the LCSS scores at baseline and at 3 weeks post CRT

\begin{tabular}{|c|c|c|c|c|}
\hline \multirow[b]{2}{*}{ Item } & \multicolumn{2}{|c|}{ Baseline $(n=20)$} & \multicolumn{2}{|c|}{$\begin{array}{c}3 \text { weeks after CRT } \\
(n=19)\end{array}$} \\
\hline & $\begin{array}{l}\text { Mean } \\
\text { (s.d.) }\end{array}$ & $\begin{array}{l}\text { Median } \\
\text { (range) }\end{array}$ & $\begin{array}{l}\text { Mean } \\
\text { (s.d.) }\end{array}$ & $\begin{array}{l}\text { Median } \\
\text { (range) }\end{array}$ \\
\hline Loss of appetite & $27.7(24.5)$ & $24(0,99)$ & $23.1(27.2)$ & $9(0,91)$ \\
\hline Fatigue $^{\mathrm{a}}$ & $35.5(27.8)$ & $31(0,95)$ & $33.8(27.2)$ & $27(0,85)$ \\
\hline Cough $^{\mathrm{a}}$ & $33.4(27.9)$ & $25(0,87)$ & $16.7(19.7)$ & $12(0,83)$ \\
\hline Dyspnea $^{\mathrm{a}}$ & $38.9(31.3)$ & $33(0,93)$ & $23.1(25.0)$ & $15(0,80)$ \\
\hline Haemoptysis & $4.3(5.1)$ & $2(0,18)$ & $2.5(2.9)$ & I $(0,8)$ \\
\hline Pain & $19.0(22.3)$ & $1 \mid(0,89)$ & $14.4(18.1)$ & II $(0,65)$ \\
\hline $\begin{array}{l}\text { Overall symptomatic } \\
\text { distress }\end{array}$ & $31.5(31.8)$ & $19(0,93)$ & $22.4(22.6)$ & $13(0,79)$ \\
\hline Normal activity & $26.7(23.9)$ & $18(0,97)$ & $29.7(30.9)$ & $12(0,98)$ \\
\hline Overall quality of life & $26.7(14.8)$ & $18(0,85)$ & $25.4(25.8)$ & II $(0,90)$ \\
\hline Mean LCSS & $27.1(16.6)$ & $28(2,62)$ & $21.2(15.6)$ & $19(1,50)$ \\
\hline
\end{tabular}

${ }^{a} N=18$ at followup assessment.

\section{DISCUSSION}

Patients with unresectable NSCLC and good PS who are unable to receive radical combined $\mathrm{CRT}$ may be treated initially with chemotherapy alone or with HDPR if there are significant local symptoms. The incremental benefit from the addition of chemotherapy to HDPR has not been defined. It however represents an important ground for investigation (Bogart, 2004), given the benefits achieved by its incorporation within the radical radiation setting.

The primary aim of this trial was therefore to identify a tolerable regimen of weekly Cisplatin and Vinorelbine combined with HDPR ( $40 \mathrm{~Gy}$ ) that could be subsequently compared to radiation alone in a randomised trial. The eligibility criteria in this study represented a heterogeneous group of patients, but all patients were at least ECOG 1 and most were not suitable for radical radiotherapy due to the extent of disease (i.e. $50 \%$ with stage IIIB and $42 \%$ stage IV disease and $30 \%$ having disease outside the irradiated volume). All patients were locally symptomatic, requiring palliation, with the majority having multiple DRS at presentation.

Of the entire cohort, 20 patients were staged by FDG-PET. This imaging mode has been shown by several studies to upstage approximately $30 \%$ of patients being considered for radical 
therapy by the detection of unsuspected metastasis. It has also been shown to provide a better correlation with survival vs conventional staging (Dunagan et al, 2001; Kalff et al, 2001; Hoekstra et al, 2003; MacManus et al, 2003). A retrospective study from our institution has also demonstrated that OS correlated with FDG-PET defined metastatic disease burden, for example, 12 months in patients with one metastatic site $v s 5$ months if greater than one site (Hicks et al, 2001; MacManus et al, 2003). On the other hand, the use of PET staging here may have led to selection bias, identifying those patients with reduced disease burden outside the chest and hence better OS relative to those staged by standard imaging as used in older studies.

The selection of patients suitable for this novel combined approach was rigorous and consistent. The inability to deliver radical CRT either for technical (extent of thoracic disease or presence of distant disease) or clinical reasons (medical comorbidities) was based on consensus following detailed discussions of the patient's case among the same cohort of medical specialists. These included thoracic radiation and medical oncologists, as well as the input of radiologists, nuclear and respiratory medicine physicians within the same tertiary referral cancer centre.

The regimen as detailed was both tolerable and showed promising activity. There was dose escalation of Vinorelbine and Cisplatin during HDPR, and the toxicities observed here defined DL 3 for evaluation in subsequent trials. The prespecified DLTs were pragmatic and clinically relevant to the treatment of such patients with a combined approach. The DLTs identified were as expected haematological, that is, grade 4 neutropenia, but overall there was only one episode of febrile neutropenia and no grade 3 radiation oesophagitis. Of note, there were no significant late oesophageal toxicities or treatment-related deaths.

The overall dose intensity of chemotherapy during CRT was approximately $90 \%$ and also in the recommended DL (DL 3), with all but one patient having received the full radiation dose. The consolidation therapy of two cycles of Cisplatin and Vinorelbine was delivered to 16 of the 24 patients overall; the toxicities observed were not unexpected for this regimen, being mainly haematological in nature. The current role of consolidation chemotherapy following either high-dose palliative or radical CRT has not been established. Two phase II trials, one of which was a three-arm randomised study, have suggested an improved survival with the addition of consolidation chemotherapy to radical CRT relative to CRT alone (Choy et al, 2002; Gandara et al, 2003). Within the limits imposed by a phase I trial design, the regimen has demonstrated promising efficacy, with a overall radiological response rate (in and out of field) of $65 \%(15 / 23)$ comprising of CR in $4 \%$ (one) and PR in $61 \%$ (14).

In the literature, there have been few studies that have addressed the issue of chemotherapy in combination with palliative radiotherapy in patients with NSCLC. In contrast to this trial, these studies have utilised hypofractionated radiation schedules with differing chemotherapy regimens. The first assessed the combination of weekly Docetaxel $\left(10-45 \mathrm{mg} \mathrm{m}^{-2}\right.$ week $\left.^{-1}\right)$ with $50 \mathrm{~Gy}, 5 \mathrm{~Gy}$ per week in 26 patients with stage III/IV disease. The response rate in 19 evaluable patients was $73.7 \%$, with the remainder having stable disease. No local recurrence was observed with this regimen. The toxicities were mainly chemotherapy-related, but palliative benefit in terms of symptom response was not recorded (Schwarzenberger et al, 2004).

A further study evaluated 50 patients with stage IV disease treated with Carboplatin ( $300 \mathrm{mg} \mathrm{m}^{-2}$, days 1 and 29) plus oral Etoposide $\left(50 \mathrm{mg} \mathrm{m}^{-2}\right.$, days $\left.1-29\right)$ and concurrent radiotherapy $28 \mathrm{~Gy}, 14 \mathrm{~Gy}$ fractions at one per week (days 1 and 8). The overall response rate was $28 \%$ with a median survival of 7 months. Nearly one-fifth of the patients had grade 3 oesophagitis and $9 \%$ had grade 3 pulmonary toxicity. Approximately $60-75 \%$ had an improvement in their local symptoms; however, a validated symptom or QOL scale was not used (Jeremic et al, 1999).
A more recent phase I study in 29 patients evaluated two such regimens as follows: (i) hypofractionated radiotherapy, $17 \mathrm{~Gy}, 8.5$ Gy fractions at one per week, combined with Vinorelbine, from 20 to $30 \mathrm{mg} \mathrm{m}^{-2}$ on days 1 and 8 every 28 days, and (ii) $60 \mathrm{~Gy}, 5-\mathrm{Gy}$ fractions at one per week, plus weekly Vinorelbine from 10 to $20 \mathrm{mg} \mathrm{m}^{-2}$, for 12 weeks. In the first regimen the DLTs were haematological, with one treatment-related toxic death, and in the second one patient suffered grade 3 oesophagitis and one had a late toxic death due to pneumonitis. Response data were not provided (Slivano et al, 2000).

It hence appears that the regimen reported here is possibly as efficacious as the hypofractionated CRT schedules, albeit with the absence of significant toxicities, most likely reflecting the reduced fraction size. The more important question remaining is whether the addition of chemotherapy to HDPR provides additional benefit to HDPR alone or to chemotherapy alone in these patients.

It is usual for patients with stage IIIB and IV patients (making up $92 \%$ of our cohort) to be treated with chemotherapy alone rather than external beam therapy. In the majority of phase III studies, stage IIIB contribute $10-40 \%$ (Frasci et al, 2000; Ranson et al, 2000; Kelly et al, 2001; Scagliotti et al, 2002; Schiller et al, 2002 ) of patients and stage IV patients would vary considerably in disease bulk outside the thorax (Frasci et al, 2000; Ranson et al, 2000; Scagliotti et al, 2002). Systemic therapy is associated with a median survival ranging from 6 to 8 months. As discussed above, the trial methodology and staging methods used in this study would preclude a direct comparison to chemotherapy-alone trials. However, local control is still relevant in patients treated with chemotherapy alone, with up to $10-50 \%$ requiring local palliative radiation. (Anderson et al, 2000; Ranson et al, 2000).

While considering the above limitations, it would be of interest to compare the results reported here with those from randomised trials of palliative radiation summarised in Table 7 . These studies are heterogenous in terms of the eligibility criteria, assessment of symptomatic benefit, treatment and staging procedures, the latter reflecting that some of these were reported in the 1980s. In comparison to our own study, similar patient cohorts and radiation schedules were assessed in the trials reported by the RTOG (Simpson et al, 1985) and the MRC (Macbeth et al, 1996). The overall radiological response and OS observed in the study reported here are comparable, and in particular may approach schedules with higher biological effective doses. However, it must be stated that the OS may have been impacted upon by selection bias generated by FDG-PET staging and also the influence of subsequent modern chemotherapy on progression.

Similar observations may be inferred by comparing the relapse patterns from this study and those of the reported trials. In this study local progression was observed in $25 \%$ of patients, with regional nodal relapse being observed in $42 \%$, the majority being isolated, perhaps indicating geographical misses or areas not attaining full radiation dose. Subject to the variation in the definition of relapse sites and imaging across studies, these results appear promising relative to the reported randomised trials of HDPR. In the RTOG study (Simpson et al, 1985) for the entire cohort, distant and local relapses were reported in 52 and $59 \%$, respectively. Local relapse ranged from $49 \%$ for the $40-\mathrm{Gy}$ split course group to $67 \%$ for the $40-\mathrm{Gy}$ continuous cohort (Simpson et al, 1985). In the MRC study, the first site of definite/suspected relapse was the primary site in $33 \%$ of the F2 and $38 \%$ of the F13 patients, and for distant sites 39\% in both (Macbeth et al, 1996).

Patient LCSS was measured prior to commencement of treatment, during and 3 weeks post-completion of CRT. PostCRT, there was a significant improvement in cough $(P=0.02)$, as well as a nonsignificant trend towards improvement in the other symptoms and parameters assessed. There was no decrement in overall QOL despite the rather intense treatment. The palliative benefits reported in our trial are consistent with the reported literature subject to dose and fractionation. The level of benefit 
Table 7 Summary of the randomised trials of high-dose palliative radiotherapy in patients with NSCLC

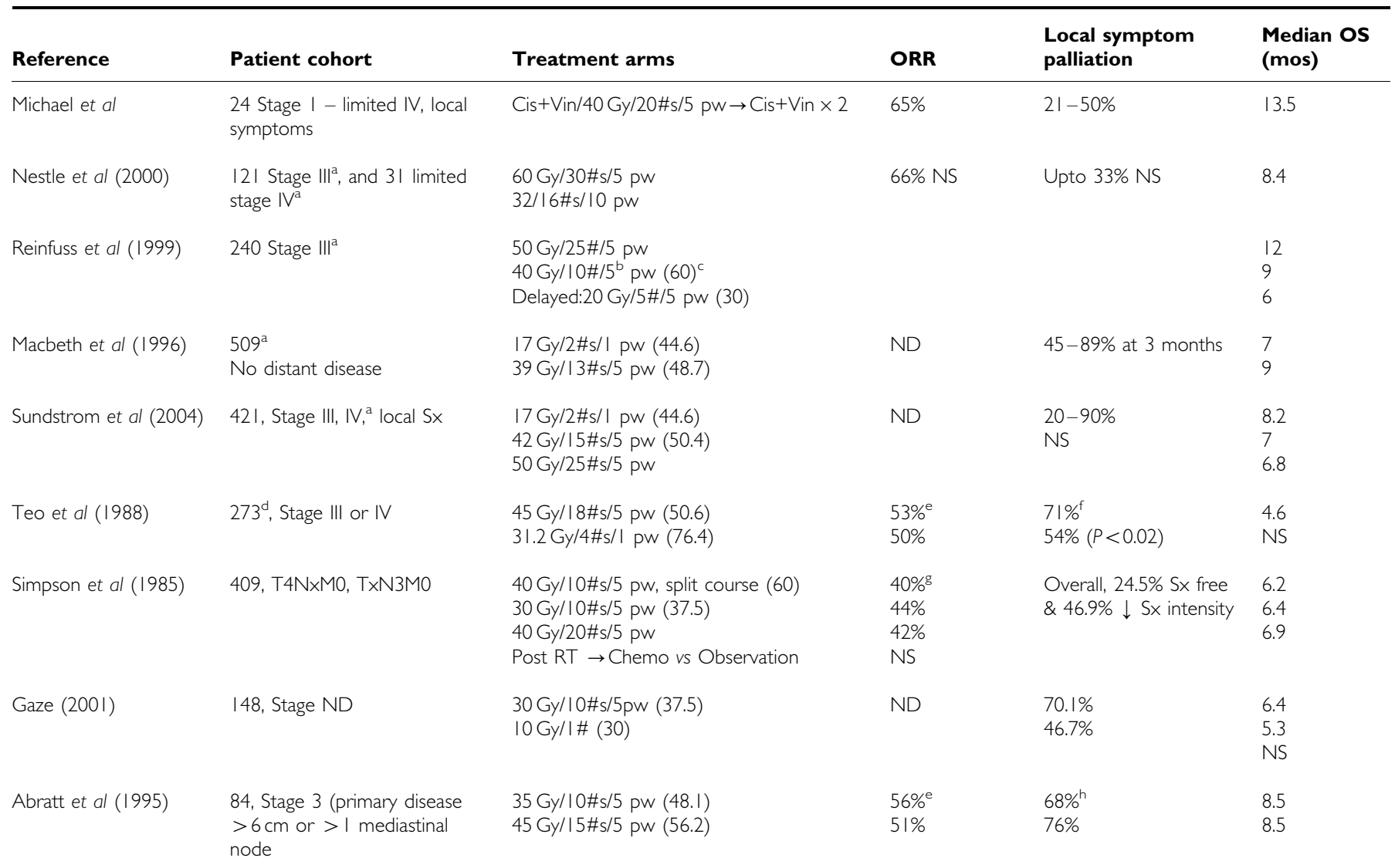

Chemo = chemotherapy; Cis = cisplatin; $N E=$ not evaluated; $N S=$ no significant difference between arms; $N D=$ not documented; Obs =observation; pw = per week; $\mathrm{RT}=$ radiotherapy; $\mathrm{S} x=$ symptoms; Vin $=$ vinorelbine. ${ }^{\mathrm{a} P a t i e n t s ~ u n s u i t a b l e ~ f o r ~ r a d i c a l ~ a p p r o a c h e s . ~}{ }^{\mathrm{b}} \mathrm{T}$ wo courses of $20 \mathrm{~Gy} / 5 \# \mathrm{~s}$ per week separated by 4 weeks. 'Biological effective dose, based on an $\alpha: \beta$ of $2 \mathrm{~Gy}$. ${ }^{d}$ Patients with bilateral pulmonary disease, N3 disease, malignant effusion, bulky tumour or nodes $>8 \mathrm{~cm}$ rendering radical therapy

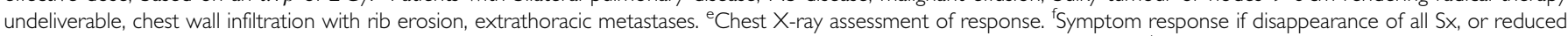
severity or frequency of one or more $\mathrm{S} x$ without the emergence of new intrathoracic symptoms. ${ }^{\text {g }}$ Radiotherapy alone arms only. ${ }^{\mathrm{h}}$ Complete and partial symptom response rate.

relative to the these studies may have been underestimated due to the short time interval from treatment completion to the final assessment of symptom benefit (Simpson et al, 1985; Macbeth et al, 1996; Sundstrom et al, 2004). In the MRC study (Macbeth et al, 1996), symptom response was assessed by the Rotterdam Symptom Checklist for the duration of the trial. The percent of patients with palliation for cough by $1 v s 2$ months post-treatment was $36 v s 48 \%$, respectively, with the other symptoms having improved by a similar trend over this time. The benefit had actually increased by an additional $14 \%$ of cases at 3 months (Macbeth et al, 1996).

In conclusion, we have therefore defined a regimen for weekly Cisplatin plus Vinorelbine combined with HDPR in patients with NSCLC not suitable for radical CRT, but of good performance status and requiring local palliation. The regimen is both tolerable with an interesting level of efficacy in terms of radiological and functional response, as well as palliative benefit. The regimen will be evaluated further as part of a national study.

\section{ACKNOWLEDGEMENTS}

The study was partly funded by a research grant from Asta Medica Oncology now Baxter Oncology.

\section{REFERENCES}

Abratt RP, Shepherd LJ, Salton DG (1995) Palliative radiation for stage 3 non-small cell lung cancer - a prospective study of two moderately high dose regimens. Lung Cancer 13: 137-143

Anderson H, Hopwood P, Stephens RJ, Thatcher N, Cottier B, Nicholson M, Milroy R, Maughan TS, Falk SJ, Bond MG, Burt PA, Connolly CK, McIllmurray MB, Carmichael J (2000) Gemcitabine plus best supportive care (BSC) vs BSC in inoperable non-small cell lung cancer - a randomized trial with quality of life as the primary outcome. UK NSCLC
Gemcitabine Group. Non-Small Cell Lung Cancer. Br J Cancer 83: 447 453

Ball D, Smith J, Bishop J, Olver I, Davis S, O’Brien P, Bernshaw D, Ryan G, Millward M (1997) A phase III study of radiotherapy with and without continuous-infusion fluorouracil as palliation for non-small-cell lung cancer. Br J Cancer 75: 690-697

Bezjak A, Dixon P, Brundage M, Tu D, Palmer MJ, Blood P, Grafton C, Lochrin C, Leong C, Mulroy L, Smith C, Wright J, Pater JL (2002) 
Randomized phase III trial of single $v s$ fractionated thoracic radiation in the palliation of patients with lung cancer (NCIC CTG SC.15). Int $J$ Radiat Oncol Biol Phys 54: 719-728

Bogart JA (2004) Hypofractionated radiotherapy for advanced non-smallcell lung cancer: is the LINAC half full? J Clin Oncol 22: 765-768

Bunn Jr PA, Kelly K (1998) New chemotherapeutic agents prolong survival and improve quality of life in non-small cell lung cancer: a review of the literature and future directions. Clin Cancer Res 4: 1087-1100

Choy H, Curran WJ, Scott CB, Bonomi P, Travis P, Haluschak J, Belani CP (2002) Preliminary report of locally advanced multimodality protocol (LAMP): ACR 427: a randomized phase II study of three chemo-radiation regimens with paclitaxel, carboplatin, and thoracic radiation (TRT) for patients with locally advanced non small cell lung cancer (LA-NSCLC). Proc Am Soc Clin Oncol 21: 1160 (abstract)

Dillman RO, Herndon J, Seagren SL, Eaton Jr WL, Green MR (1996) Improved survival in stage III non-small-cell lung cancer: seven-year follow-up of cancer and leukemia group B (CALGB) 8433 trial. J Natl Cancer Inst 88: 1210-1215

Dunagan D, Chin Jr R, McCain T, Case L, Harkness B, Oaks T, Haponik E (2001) Staging by positron emission tomography predicts survival in patients with non-small cell lung cancer. Chest 119: 333-339

Edelstein MP, Wolfe III LA, Duch DS (1996) Potentiation of radiation therapy by vinorelbine (Navelbine) in non-small cell lung cancer. Semin Oncol 23: $41-47$

Frasci G, Lorusso V, Panza N, Comella P, Nicolella G, Bianco A, De Cataldis G, Iannelli A, Bilancia D, Belli M, Massidda B, Piantedosi F, Comella G, De Lena M (2000) Gemcitabine plus vinorelbine $v s$ vinorelbine alone in elderly patients with advanced non-small-cell lung cancer. J Clin Oncol 18: $2529-2536$

Gandara DR, Chansky K, Albain KS, Leigh BR, Gaspar LE, Lara Jr PN, Burris H, Gumerlock P, Kuebler JP, Bearden III JD, Crowley J, Livingston R (2003) Consolidation docetaxel after concurrent chemoradiotherapy in stage IIIB non-small-cell lung cancer: phase II Southwest Oncology Group Study S9504. J Clin Oncol 21: 2004-2010

Gaze MN, Kelly CG, Kerr GR, Cull A, MacDougall RH, Howard GCW, Cowie VJ, Price A (2001) Fractionated thoracic radiotherapy gives better symptom relief in patients with non-small cell lung cancer. Eur J Cancer 37(Suppl 6): 95 (abstr)

Hicks RJ, Kalff V, MacManus MP, Ware RE, Hogg A, McKenzie AF, Matthews JP, Ball DL (2001) (18)F-FDG PET provides high-impact and powerful prognostic stratification in staging newly diagnosed non-small cell lung cancer. J Nucl Med 42: 1596-1604

Hoekstra CJ, Stroobants SG, Hoekstra OS, Vansteenkiste J, Biesma B, Schramel FJ, van Zandwijk N, van Tinteren H, Smit EF (2003) The value of [18F]fluoro-2-deoxy-D-glucose positron emission tomography in the selection of patients with stage IIIA-N2 non-small cell lung cancer for combined modality treatment. Lung Cancer 39: 151-157

Hoffman PC, Cohen EE, Masters GA, Haraf DJ, Mauer AM, Rudin CM, Krauss SA, Huo D, Vokes EE (2002) Carboplatin plus vinorelbine with concomitant radiation therapy in advanced non-small cell lung cancer: a phase I study. Lung Cancer 38: 65-71

Hollen PJ, Gralla RJ, Kris MG, Potanovich LM (1993) Quality of life assessment in individuals with lung cancer: testing the Lung Cancer Symptom Scale (LCSS). Eur J Cancer 29A(Suppl 1): S51-S58

Jeremic B, Shibamoto Y, Milicic B, Milisavljevic S, Nikolic N, Dagovic A, Radosavljevic-Asic G (1999) Short-term chemotherapy and palliative radiotherapy for elderly patients with stage IV non-small cell lung cancer: a phase II study. Lung Cancer 24: 1-9

Kalff V, Hicks RJ, MacManus MP, Binns DS, McKenzie AF, Ware RE, Hogg A, Ball DL (2001) Clinical impact of (18)F fluorodeoxyglucose positron emission tomography in patients with non-small-cell lung cancer: a prospective study. J Clin Oncol 19: 111-118

Kelly K, Crowley J, Bunn Jr PA, Presant CA, Grevstad PK, Moinpour CM, Ramsey SD, Wozniak AJ, Weiss GR, Moore DF, Israel VK, Livingston RB, Gandara DR (2001) Randomized phase III trial of paclitaxel plus carboplatin $v s$ vinorelbine plus cisplatin in the treatment of patients with advanced non-small-cell lung cancer: a Southwest Oncology Group trial. J Clin Oncol 19: 3210-3218

Kramer GWPM, Wanders SL, Noordijk EM, Vonk EJA, Uitterhoeve ALJ, Bussink J, Leest AHDvd, van Houwelingen JC, van den Hout WB, Lee JWH (2003) Randomized Dutch national study of the effect of irradiation with different treatment schemes in the palliation of non-smalll cell lung cancer. Lung Cancer 41: S38

Le Chevalier T, Pujol JL, Douillard JY, Alberola V, Monnier A, Riviere A, Lianes P, Chomy P, Cigolari S, Besson F (1994) A three-arm trial of vinorelbine (Navelbine) plus cisplatin, vindesine plus cisplatin, and single-agent vinorelbine in the treatment of non-small cell lung cancer: an expanded analysis. Semin Oncol 21: 28-33

Macbeth FR, Bolger JJ, Hopwood P, Bleehen NM, Cartmell J, Girling DJ, Machin D, Stephens RJ, Bailey AJ (1996) Randomized trial of palliative two-fraction $v s$ more intensive 13-fraction radiotherapy for patients with inoperable non-small cell lung cancer and good performance status. Medical Research Council Lung Cancer Working Party. Clin Oncol ( $R$ Coll Radiol) 8: 167-175

MacManus MR, Hicks R, Fisher R, Rischin D, Michael M, Wirth A, Ball DL (2003) FDG-PET-detected extracranial metastasis in patients with nonsmall cell lung cancer undergoing staging for surgery or radical radiotherapy - survival correlates with metastatic disease burden. Acta Oncol 42: $48-54$

Masters GA, Haraf DJ, Hoffman PC, Drinkard LC, Krauss SA, Ferguson MK, Olak J, Samuels BL, Golomb HM, Vokes EE (1998) Phase I study of vinorelbine, cisplatin, and concomitant thoracic radiation in the treatment of advanced chest malignancies. J Clin Oncol 16: 2157-2163

Miller AB, Hogestraeten B, Staquet M, Winkler A (1981) Reporting results of cancer treatment. Cancer 47: 207-214

MRC Lung Cancer Working Party (1991) Inoperable non-small-cell lung cancer (NSCLC): a Medical Research Council randomised trial of palliative radiotherapy with two fractions or ten fractions. $\mathrm{Br} J$ Cancer 63: $265-270$

MRC Lung Cancer Working Party (1992) A Medical Research Council (MRC) randomised trial of palliative radiotherapy with two fractions or a single fraction in patients with inoperable non-small-cell lung cancer (NSCLC) and poor performance status. Br J Cancer 65: 934-941

Nestle U, Nieder C, Walter K, Abel U, Ukena D, Sybrecht GW, Schnabel K (2000) A palliative accelerated irradiation regimen for advanced nonsmall-cell lung cancer $v s$ conventionally fractionated $60 \mathrm{GY}$ : results of a randomized equivalence study. Int J Radiat Oncol Biol Phys 48: 95-103

Plataniotis GA, Kouvaris JR, Dardoufas C, Kouloulias V, Theofanopoulou MA, Vlahos L (2002) A short radiotherapy course for locally advanced non-small cell lung cancer (NSCLC): effective palliation and patients' convenience. Lung Cancer 35: 203-207

Quddus AM, Kerr GR, Price A, Gregor A (2001) Long-term survival in patients with non-small cell lung cancer treated with palliative radiotherapy. Clin Oncol ( $R$ Coll Radiol) 13: 95-98

Ranson M, Davidson N, Nicolson M, Falk S, Carmichael J, Lopez P, Anderson H, Gustafson N, Jeynes A, Gallant G, Washington T, Thatcher N (2000) Randomized trial of paclitaxel plus supportive care $v s$ supportive care for patients with advanced non-small-cell lung cancer. J Natl Cancer Inst 92: 1074-1080

Reinfuss M, Glinski B, Kowalska T, Kulpa J, Zawila K, Reinfuss K, Dymek P, Herman K, Skolyszewski J (1999) Radiotherapy for stage III, inoperable, asymptomatic small cell lung cancer. Final results of a prospective randomized study (240 patients). Cancer Radiother 3: 475-479

Sause WT, Scott C, Taylor S, Johnson D, Livingston R, Komaki R, Emami B, Curran WJ, Byhardt RW, Turrisi AT (1995) Radiation Therapy Oncology Group (RTOG) 88-08 and Eastern Cooperative Oncology Group (ECOG) 4588: preliminary results of a phase III trial in regionally advanced, unresectable non-small-cell lung cancer. J Natl Cancer Inst 87: 198-205

Scagliotti GV, De Marinis F, Rinaldi M, Crino L, Gridelli C, Ricci S, Matano E, Boni C, Marangolo M, Failla G, Altavilla G, Adamo V, Ceribelli A, Clerici M, Di Costanzo F, Frontini L, Tonato M (2002) Phase III randomized trial comparing three platinum-based doublets in advanced non-small-cell lung cancer. J Clin Oncol 20: 4285-4291

Schaafsma J, Coy P (2000) Response of global quality of life to high-dose palliative radiotherapy for non-small-cell lung cancer. Int J Radiat Oncol Biol Phys 47: 691-701

Schaake-Koning C, van den Bogaert W, Dalesio O, Festen J, Hoogenhout J, van Houtte P, Kirkpatrick A, Koolen M, Maat B, Nijs A (1992) Effects of concomitant cisplatin and radiotherapy on inoperable non-small-cell lung cancer. $N$ Engl J Med 326: $524-530$

Schiller JH, Harrington D, Belani CP, Langer C, Sandler A, Krook J, Zhu J, Johnson DH (2002) Comparison of four chemotherapy regimens for advanced non-small-cell lung cancer. $N$ Engl J Med 346: 92 -98

Schwarzenberger P, Theodossiou C, Barron S, Diethelm L, Boyle M, Harrison L, Wynn RB, Salazar OM, Fariss A (2004) Dose escalation of docetaxel concomitant with hypofractionated, once weekly chest radiotherapy for non-small-cell lung cancer: a phase I study. Am J Clin Oncol 27: $395-399$

Simpson JR, Francis ME, Perez-Tamayo R, Marks RD, Rao DV (1985) Palliative radiotherapy for inoperable carcinoma of the lung: final report 
of a RTOG multi-institutional trial. Int J Radiat Oncol Biol Phys 11: $751-758$

Slivano G, Campoccia S, Colosimo S, Moda S, Luppatelli, Maranzano E (2000) Vinorelbine and hypofractionated radiotherapy as a palliative treatment in patients affected by non small cell lung cancer: a phase I study. Proc Am Soc Clin Oncol 19: 2048 (abstract)

Sundstrom S, Bremnes R, Aasebo U, Aamdal S, Hatlevoll R, Brunsvig P, Johannessen DC, Klepp O, Fayers PM, Kaasa S (2004) Hypofractionated palliative radiotherapy ( $17 \mathrm{~Gy}$ per two fractions) in advanced non-smallcell lung carcinoma is comparable to standard fractionation for symptom control and survival: a national phase III trial. J Clin Oncol 22: $801-810$

Teo P, Tai TH, Choy D, Tsui KH (1988) A randomized study on palliative radiation therapy for inoperable non small cell carcinoma of the lung. Int J Radiat Oncol Biol Phys 14: 867-871
The Elderly Lung Cancer Vinorelbine Italian Study Group (1999) Effects of vinorelbine on quality of life and survival of elderly patients with advanced non-small-cell lung cancer. I Natl Cancer Inst 91: $66-72$

Vokes EE, Herndon II JE, Crawford J, Leopold KA, Perry MC, Miller AA, Green MR (2002) Randomized phase II study of cisplatin with gemcitabine or paclitaxel or vinorelbine as induction chemotherapy followed by concomitant chemoradiotherapy for stage IIIB non-smallcell lung cancer: cancer and leukemia group B study 9431. J Clin Oncol 20: $4191-4198$

Zatloukal P, Petruzelka L, Zemanova M, Havel L, Janku F, Judas L, Kubik A, Krepela E, Fiala P, Pecen L (2004) Concurrent vs sequential chemoradiotherapy with cisplatin and vinorelbine in locally advanced nonsmall cell lung cancer: a randomized study. Lung Cancer 46: 87-98 